ORIGINAL ARTICLE

\title{
Facilitators and Barriers for Using Outcome Measuring Tools in Physical Therapy Practice
}

\author{
RAHAT AYUB ${ }^{1}$, SOMIA SABEEH AWAN ${ }^{2}$, MUHAMAMD RIZWAN ${ }^{1}$, RABIA MAJEED ${ }^{1}$, RABIA JAWA ${ }^{1}$, TAMKNAT ILYAS ${ }^{1}$ \\ ${ }^{1}$ Lecturer Department of Physical Medicine and Rehabilitation, School of Health Science, UMT Lahore \\ ${ }^{2}$ Assistant Professor/COD, Department of Physical Medicine and Rehabilitation, School of Health Science, UMT Lahore \\ Corresponding author: Rahat Ayub, Email: rahat.ayub@umt.edu.pk, Contact No.+923234087940
}

\begin{abstract}
Objective: The study was conducted toascertain the percentage of physiotherapist who were utilizing the outcome measures during the treatment of patients and to find the factors which were potentiating the physiotherapists in implementing the outcome measuring tools in the treatment of their patients. On the other hand, such factors were also looked into which were considered as obstacles by the physiotherapists in the use of the tools.

Methodology: The estimated study population size was 242. Data was collected through e-mail as well as through one-on-one meeting with the physiotherapists by using a standard questionnaire (appendix I) and was analyzed through SPSS version 20.

Results: It was found that 78 percent of the study participants were using the outcome measures in the assessments of the patients and for finding the progression in their condition. The feeling of the patient about the keen involvement of the physiotherapist in his treatment, enhanced communication between two of them and increased efficiency of examination were the major facilitators which urged the physiotherapists to use outcome measures in their practice. The most frequent barriers seen were the duration required by physiotherapist to analyze the score and duration of patient to complete it.

Conclusion: The main facilitators are increased communication between physiotherapist and patient and enhanced the efficacy of assessment. Alternatively, the main barriers restricting the usage of outcome measures are reported to be the inability to complete the various assessment tools due to the lack of time on the part of the patient as well as the physical therapist.

Key words: Outcome measures, Outcomes measuring tools, Facilitators, Barriers, Physical therapist, Physiotherapist
\end{abstract}

\section{INTRODUCTION}

For a diseased person, there are several scales questionnaires are available to assess the difference in the current disease status and improvement in condition after therapy. These are also helpful to have an understanding of the patient and better interpretation of his condition and improvement. These scales and questionnaires are known in literature as "disability measures," "outcome measures," "outcome measuring tools "quality-of-life measures" and "assessment outcomes". 1

The use of few outcome measures have a significant role in the assessment of success of therapy, especially physiotherapy, and also it can help with accountability and confirms the quality provision. ${ }^{2}$ In order to show their professional obligation, physiotherapists need to determine the outcome measures of physiotherapy. In order for patients to be happy with their care, it is important to give them an indication of the prognosis. The need to incorporate outcome indicators is welcomed not only to assess the changes made, but also to consider the expectations and satisfaction of patients. ${ }^{3}$

Guidelines for clinical practice developed by several countries require the use of common measurement instruments to ensure the provision of quality care to patients by continuously measuring the variables initially evaluated. But, regarding use of indicators to standardize the outcome, there is a lack of adherence among the physiotherapists. The need for physiotherapists to use standardized outcome indicators is the ultimate necessity of time to secure the patient's right to be measured by standardized methods. ${ }^{1}$
The suggested benefits of using the outcome measures are building the recommendations on the costeffective treatment of particular conditions, predicting the success of physiotherapist and helping to classify patients with bad prognosis, despite the fact that no clinical study has been performed on the direct effects of using outcome measures. As the debate for evidence-based therapy has grown, health-care providers have now become more responsible for the effects of their treatment. 4

Time to assess the outcome measure is the main barriers to implement the outcome measure tools. In addition, clinicians do not consider recorded outcome measures to be accurate for patients. Limited work has been done in literature to identify obstacles and facilitators to the use of outcome measures. ${ }^{5}$ The purpose of the study is to collect data on the use of outcome measures and to identify benefits and barriers to their use as there is a lack of knowledge among physical therapists in Pakistan on the use of outcome measures.

\section{METHODOLOGY}

This cross sectional study was conducted at different government and private clinicsproviding service of physical therapy in Lahore for 6 months. About 242 physiotherapist were selected by simple random sampling. Physical therapists working in clinical setup since 1 year or more were included in the study. Data was collected by using a questionnaire. Barriers were considered as the factors that causehindrances intherapy in using outcome measures. These hindrancesare faced while assessing the improvement through the application of "outcome 
measuring tools". Data was analyzed using IBM-SPSS version 20

\section{RESULTS}

Out of 242 physiotherapists, 101 were males and 141 were females. About $46 \%$ had tDPT, M.S. or M.Phil degree while $36 \%$ were DPT, $46.7 \%$ had tDPT, M.S. or M. Phildegree in any domain of physiotherapy. Alternatively, only $0.4 \%$ had completed the PhD degree, $36.8 \%$ had DPT degree and $16.1 \%$ had only BSc Hons Physiotherapy. About $53.3 \%$ were working in their private clinics, $31.4 \%$ were working in government sector health care facilities while $15.3 \%$ were providing the services at home.

26.9 of the physiotherapists had an experience of 1 year, 37.6 percent were having 2-5 years of practice experience whereas, 28.1 percent of the participants had an experience comprising 6-8 years. While, participants with experience of more than 10 years comprised only 7.1 percent of the total study population.

Interest in orthopedics was held by 38.4 percent of the study population. 16.1 percent of the population had interest in sports physiotherapy. Cardiopulmonary physiotherapy was the favorite of the 15.7 percent of the population. Neurological physiotherapy lovers were 14.6 percent and 14 percent of the population had interest in pediatrics.

Of the 242 participants, $189(78 \%)$ said that they were using the outcome measuring tools. Mostly $(91.5 \%)$ feels that using outcome measuring tools helps to make patients feel that physiotherapist has a deep interest in their treatment, it enhance communication between therapist and patient (85\%) and $75 \%$ through it increase the efficiency of examination. The most common barrier of using outcome measuring tool is duration required by physiotherapist to analyze the score $(88.4 \%)$ and also the duration required by patient to fill it $(81.5 \%)$.

Many major uses of outcome measures were the determination of treatment efficacy given (82\%) and communication with other medical personnel (86.2\%). The recurrent causes for adopting the outcome measuring tools is that it's easy for patients to understand $(89.9 \%)$ and could be complete easily ( $86.2 \%)$. There were $22 \%$ nonusers of outcome measuring tools. The main reason for not using this tool is thought that it requires higher knowledge $(90.6 \%)$, English language (88.7\%), non-availability of plan direction (83\%) and incomplete outcome measures at the time of discharge. According to this, 78percent of the physiotherapists are using the outcome measuring tools whereas, 22 percent of the study population is not using the outcome measuring tools.

\begin{tabular}{|c|c|}
\hline $\mathrm{n}$ & 242 \\
\hline \multicolumn{2}{|l|}{ Gender } \\
\hline Male & 101 \\
\hline Female & 141 \\
\hline \multicolumn{2}{|l|}{ Highest degree } \\
\hline B.Sc. Hons Physiotherapy & $161 \%$ \\
\hline DPT & $36.8 \%$ \\
\hline tDPT/M/phil/MS & $46 \%$ \\
\hline $\mathrm{PhD}$ & $0.4 \%$ \\
\hline \multicolumn{2}{|c|}{ Doing treatment sessions daily (hours) } \\
\hline $2-3$ & $19.01 \%$ \\
\hline $4-6$ & $52.07 \%$ \\
\hline $6-8$ & $28.93 \%$ \\
\hline \multicolumn{2}{|l|}{ Clinical Settings } \\
\hline Privately owned OPD clinic & $129(53.3 \%)$ \\
\hline Government based OPD clinic & $76(31.4 \%)$ \\
\hline Home Care & $37(15.3 \%)$ \\
\hline \multicolumn{2}{|l|}{ Number of years practiced } \\
\hline 1 year & 26.9 \\
\hline $2-5$ years & 37.6 \\
\hline $6-10$ years & 28.1 \\
\hline$>10$ years & 7.1 \\
\hline \multicolumn{2}{|l|}{ Area of interest } \\
\hline None & 1.2 \\
\hline CVS \& Pulmonary & 15.7 \\
\hline Neurology & 14.6 \\
\hline Orthopedic & 38.4 \\
\hline Pediatric & 14 \\
\hline Sports & 16.1 \\
\hline \multicolumn{2}{|l|}{ Type of patients treated } \\
\hline Musculoskeletal & 22.3 \\
\hline Neurological & 23.1 \\
\hline CVS \& pulmonary & 10 \\
\hline Women's health condition & 12 \\
\hline Other & 32.6 \\
\hline
\end{tabular}

Figure 1:Use of the health status questionnaires by physiotherapists

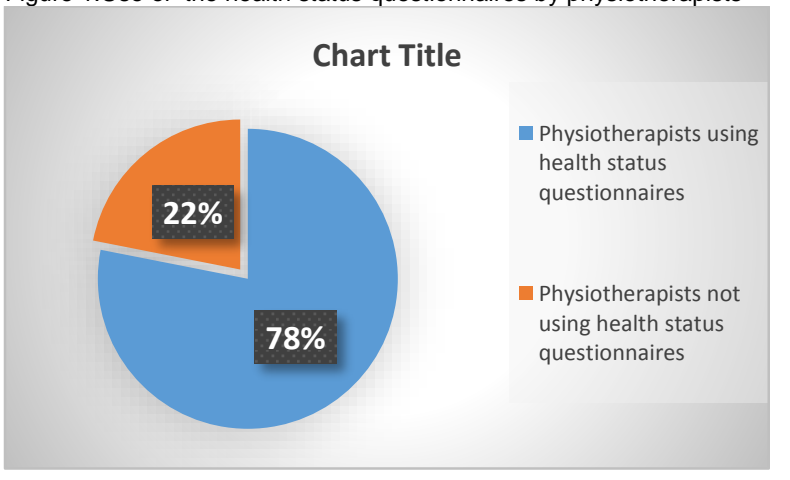

Table 2: Data provided by the physiotherapists who were not using the health status questionnaires

\begin{tabular}{|c|c|c|}
\hline Reasons behind not using the outcome measuring tools & Yes & No \\
\hline Are confusing to patients & 32 & 21 \\
\hline Are difficult for patients to complete independently & 21 & 32 \\
\hline Require too high a reading level & 48 & 5 \\
\hline Are in English, a language in which many of my patients are not fluent & 47 & 6 \\
\hline Make patients anxious & 3 & 5 \\
\hline Require more effort than they are worth & 10 & 43 \\
\hline Don't contain information that helps to direct the plan of care & 44 & 9 \\
\hline Are difficult to interpret(e.g., don't know what norms are, or how score relates to severity or what clinically important change might be) & 1 & 52 \\
\hline Don't contain the types of items or questions that are relevant for the type of patients I see & 3 & 50 \\
\hline Often don't get completed at discharge, so cannot give information about patient's' response to treatment & 45 & 8 \\
\hline Require training that I do not have & 9 & 44 \\
\hline Cost too much & 1 & 52 \\
\hline Require a support structure that I don't have & 6 & 47 \\
\hline Are really only useful for research purposes & 44 & 9 \\
\hline Are not relevant because my practice involves consultation, case management & 19 & 34 \\
\hline
\end{tabular}


Table 3: Data provided by the physiotherapists who were using the health status questionnaires

\begin{tabular}{|c|c|c|c|}
\hline Benefits of using outcome measuring tools & $\begin{array}{l}\text { Definitely } \\
\text { agree }\end{array}$ & Agree & $\begin{array}{l}\text { Somewhat } \\
\text { Disagree }\end{array}$ \\
\hline Helping to direct the plan of care & 74 & 96 & 19 \\
\hline Enhancing communication between therapist and patient & 152 & 26 & 11 \\
\hline Helping patients feel that therapists are thorough in their examination & 173 & 11 & 5 \\
\hline Increasing the efficiency of examinations & 142 & 39 & 8 \\
\hline Helping to focus choice of interventions & 95 & 74 & 20 \\
\hline Attaining better patient outcome & 86 & 69 & 34 \\
\hline Helping to motivate and encourage patients & 117 & 61 & 11 \\
\hline Enhanced marketing of my practice or services & 66 & 92 & 31 \\
\hline \multicolumn{4}{|l|}{ Problems reported by the physiotherapists in using the outcome measuring tools } \\
\hline Are confusing to patients & 70 & 98 & 21 \\
\hline Are difficult for patients to complete independently & 107 & 83 & 0 \\
\hline Require too high a reading level & 136 & 48 & 5 \\
\hline Are in English, a language in which many of my patients are not fluent & 87 & 76 & 26 \\
\hline Require more effort than they are worth & 79 & 86 & 24 \\
\hline Don't contain information that helps to direct the plan of care & 87 & 92 & 10 \\
\hline Are difficult to interpret & 97 & 80 & 12 \\
\hline Make patients anxious & 31 & 103 & 55 \\
\hline Take too much time for patients to complete & 154 & 26 & 9 \\
\hline Take too much of clinicians' time to analyze/calculate/score & 167 & 18 & 4 \\
\hline Don't contain the types of items or questions that are relevant for the type of patients I see & 52 & 93 & 44 \\
\hline $\begin{array}{l}\text { Often dont get completed at discharge, so cannot give information about paients' response to } \\
\text { treatment }\end{array}$ & 48 & 79 & 62 \\
\hline
\end{tabular}

Table 4: Reasons for using outcome measuring tools by the physiotherapists

\begin{tabular}{|c|c|c|c|}
\hline Uses & $\begin{array}{l}\text { Yes } \\
\text { routinely, }\end{array}$ & $\begin{array}{l}\text { Yes } \\
\text { sometimes }\end{array}$ & No \\
\hline Answering clinical questions through a traditional research approach & 15 & 62 & 112 \\
\hline Quality improvement/assurance activities & 37 & 140 & 12 \\
\hline Determining the complexity of patients & 27 & 152 & 10 \\
\hline comparing performance across therapists in terms of average patient outcomes & 10 & 20 & 159 \\
\hline Comparing one's clinical performance to that of other clinics & 7 & 26 & 156 \\
\hline Comparing average outcomes of patients with different conditions within a practice & 20 & 74 & 95 \\
\hline $\begin{array}{l}\text { Examining the average change in patients' health status over their episodes of care to determine a } \\
\text { practice's effectiveness }\end{array}$ & 155 & 32 & 2 \\
\hline $\begin{array}{l}\text { Examining the average change in patients; health status over their episodes of care to determine } \\
\text { individual therapists' effectiveness }\end{array}$ & 124 & 65 & 0 \\
\hline $\begin{array}{l}\text { Examining and documenting the status, progress and/or outcomes of individual patients by } \\
\text { individual therapists }\end{array}$ & 65 & 120 & 4 \\
\hline Communicating with other health care providers and referral resources & 163 & 14 & 12 \\
\hline
\end{tabular}

Table 5: Criterion used for selecting the outcome measuring tools

\begin{tabular}{|l|l|l|}
\hline Criteria & Yes & No \\
\hline Can be completed easily & 163 & 26 \\
\hline Easy for patient to understand & 170 & 19 \\
\hline $\begin{array}{l}\text { Easy for clinicians to understand/interpret } \\
\text { meaning of scores and change in scores }\end{array}$ & 136 & 53 \\
\hline Shown to be valid and reliable & 175 & 14 \\
\hline $\begin{array}{l}\text { Seem to be most common ones used in } \\
\text { physical therapy practice }\end{array}$ & 9 & 180 \\
\hline $\begin{array}{l}\text { useful for a variety of purposes such as } \\
\text { research, quality assurance, patient } \\
\text { evaluation }\end{array}$ & 119 & 70 \\
\hline Can be analyzed electronically & 0 & 189 \\
\hline $\begin{array}{l}\text { Most appropriate for the types of conditions } \\
\text { seen in my practice settings }\end{array}$ & 11 & 178 \\
\hline
\end{tabular}

\section{DISCUSSION}

In order to find the proportion of physical therapists using the outcome steps, the analysis was carried out. In addition, significant facilitators and inhibitors were also found in the physiotherapists' use of outcome measurement methods. The key results were the trust of the patient in the therapist as the key facilitator and the long period taken to complete the outcome steps. Other major facilitators were the confidence of patient in skills of his physiotherapist, better communication between physiotherapist and patients and high proficiency of examining the patient. Jatte et al., also reported improved communication as the plus point of using the outcome measuring tools. ${ }^{6}$

The most common barriers are prolonged time of completing and analyzing the outcome measuring tools by patients and by physiotherapist, respectively and high level of reading it. Old researches have explored that short time duration to complete the outcome measure tool was the major barrier. ${ }^{7}$

In order to assess the effectiveness of the care offered and to interact with other health providers, outcome measurement instruments were used. It has been proposed that the in order to determine the progress of practice and treatment, the outcome measuring tools were used. The main factors leading to its successful use were accuracy, reliability, short duration for completion and easy understanding. ${ }^{8}$ 
While regarding the non-use of outcome measuring tools, it has been proposed that requirement of high level of knowledge and difficulty in completing it due to English language were the barrier for patients were the most common reasons for not using them. Burton et al., explored the opinions of physiotherapists regarding barriers and facilitators for using outcome measures tool. They proposed that short time duration, less training and inadequate knowledge about tool and its benefits were the significant barriers. While the most probable facilitators were the efficiency in providing the knowledge regarding improvement of patients' condition an also the working therapy method. ${ }^{9}$

Furthermore, it has been suggested that high qualification, more information and more experience about using outcome measures had a positive effect on the use of outcome measures. Management of the assistance form and support from colleagues was also the facilitator for the implementation of outcome steps. While, lack of funds and time, inappropriate knowledge about accuracy and predictability as well as inappropriate precision about importance of outcome measures had a negative impact of using outcome measures. ${ }^{10}$

Francis et al., piloted a study to know that which factors are most common that affect the practice of using the outcome measures among physiotherapists. The most responsible factors were the knowledge of physiotherapist regarding outcome measures, availability of several facilities and professional attitude of physiotherapist regarding use of outcome measures. ${ }^{2}$ Diane et al., also conducted study to observe the facilitators and barriers for outcome measures use. The response rate was around $50 \%$. Several barriers were observed to be related significantly to use of outcome measures. These are short time, lack of funds and inappropriate knowledge on patient's side and also the physiotherapist about the outcome measures. ${ }^{1}$

Roland et al., conducted a study on physiotherapist working for stroke patients and explored a positive relationship between outcome measures and understanding of these outcome measures, which was the most motivating factor for their use in routine. However, the short time duration and limited resources were also the hindrances which were hindering the use of outcome measures. ${ }^{11}$

Copeland et al., conducted a study to determine the use of outcomes measures among physiotherapist who were working on patients of low back pain. They suggested that the higher qualification and more appropriate information about outcome measures had significant impact on use of outcome measures while the short time was the main cause of not using them. ${ }^{12}$

\section{CONCLUSION}

The main facilitators are increased communication between physiotherapist and patient and enhanced the efficacy of assessment. Alternatively, the main barriers restricting the usage of outcome measures are reported to be the inability to complete the various assessment tools due to the lack of time on the part of the patient as well as the physical therapist.

\section{REFERENCES}

1. Jette DU, Halbert J, Iverson C, Miceli E, Shah P. Use of Standardized Outcome Measures in Physical Therapist Practice: Perceptions and Applications. Physical Therapy 2009;89(2):125-35.

2. Francis R. Report of the Mid Staffordshire NHS Foundation Trust Public Inquiry: Executive Summary2013.

3. Ostelo R. Physiotherapy management of sciatica. Journal of Physiotherapy 2020 04/01;66.

4. Jette DU, Bacon K, Batty C, Carlson M, Ferland A, Hemingway RD, et al. Evidence-Based Practice: Beliefs, Attitudes, Knowledge, and Behaviors of Physical Therapists. Physical Therapy 2003;83(9):786805.

5. Wedge FM, Braswell-Christy J, Brown CJ, Foley KT, Graham C, Shaw S. Factors influencing the use of outcome measures in physical therapy practice. Physiotherapy theory and practice 2012 Feb;28(2):119-33.

6. Jette DU, Jewell DV. Use of quality indicators in physical therapist practice: an observational study. Phys Ther 2012 Apr;92(4):507-24.

7. Tyson S, Burton L, McGovern A. The impact of a toolkit on use of standardised measurement tools in stroke rehabilitation. Clinical Rehabilitation 2015;29(9):926-34.

8. Mehta S, Grafton K. A survey on the use of outcome measures by musculoskeletal physiotherapist's in India. Physiotherapy theory and practice 2014 2014/02/01;30(2):110-22.

9. Burton LJ, Tyson S, McGovern A. Staff perceptions of using outcome measures in stroke rehabilitation. Disability and rehabilitation 2013 May;35(10):828-34.

10. Duncan EA, Murray J. The barriers and facilitators to routine outcome measurement by allied health professionals in practice: a systematic review. BMC health services research 2012 May 22;12:96.

11. Van Peppen RP, Maissan FJ, Van Genderen FR, Van Dolder R, Van Meeteren NL. Outcome measures in physiotherapy management of patients with stroke: a survey into self-reported use, and barriers to and facilitators for use. Physiotherapy research international : the journal for researchers and clinicians in physical therapy 2008 Dec;13(4):255-70.

12. Copeland JM, Taylor WJ, Dean SG. Factors influencing the use of outcome measures for patients with low back pain: a survey of New Zealand physical therapists. Phys Ther 2008 Dec;88(12):1492-505.

13. Al-Muqiren, T.N., Al-Eisa, E.S., Alghadir, A.H. and Anwer, S., 2017. Implementation and use of standardized outcome measures by physical therapists in Saudi Arabia: barriers, facilitators and perceptions. BMC health services research, 17(1), pp.1-10.

14. Braun, T., Rieckmann, A., Weber, F. and Grüneberg, C., 2018. Current use of measurement instruments by physiotherapists working in Germany: a cross-sectional online survey. BMC health services research, 18(1), pp.1-16.

15. Demers, M., Blanchette, A.K., Mullick, A.A., Shah, A., Woo, K., Solomon, J. and Levin, M.F., 2019. Facilitators and barriers to using neurological outcome measures in developed and developing countries. Physiotherapy Research International, 24(1), p.e1756.

16. Meerhoff, G.A., van Dulmen, S.A., Maas, M.J., Bakker-Jacobs, A. Nijhuis-Van der Sanden, M.W. and van der Wees, P.J., 2019. Exploring the perspective of patients with musculoskeletal health problems in primary care on the use of patient-reported outcome measures to stimulate quality improvement in physiotherapist practice; a qualitative study. Physiotherapy theory and practice, pp.112.

17. Briggs, M.S., Rethman, K.K., Crookes, J., Cheek, F., Pottkotter, K., McGrath, S., DeWitt, J., Harmon-Matthews, L.E. and Quatman-Yates, C.C., 2020. Implementing patient-reported outcome measures in outpatient rehabilitation settings: A systematic review of facilitators and barriers using the Consolidated Framework for Implementation Research. Archives of physical medicine and rehabilitation.

18. Agyenkwa, S.K., Yarfi, C., Banson, A.N., Kofi-Bediako, W.A., Abonie, U.S., Angmorterh, S.K. and Ofori, E.K., 2020. Assessing the Use of Standardized Outcome Measures for Stroke Rehabilitation among Physiotherapists in Ghana. Stroke Research and Treatment, 2020. 